\title{
EL TESORO PERDIDO DE GUARRAZAR
}

\author{
POR
}

\author{
LUIS J. BALMASEDA MUNCHARAZ \\ Sección de Arqueologia Paleocristiana y Visigoda. \\ Museo Arqueológico Nacional. Madrid.
}

\section{RESUMEN}

El Tesoro de Guarrazar, hallado en 1858 y conservado hoy en tres Instituciones, sufrió la destrucción de numerosos componentes. En este trabajo se intenta una aproximación a las joyas desaparecidas, a través de declaraciones de testigos coetáneos y partiendo de los fragmentos conservados. Una de las piezas más significativas debió ser la gran cruz-relicario con alfa y omega pendientes, de la que sólo quedan dos láminas de revestimiento en oro y piedras preciosas y una de las letras.

\section{SUMMARY}

The Treasure of Guarrazar was found in 1858 and actually it is kept by three institutions. It suffered the parcial or total destruction of some constituents. This paper trues to reach an approximation to the missed jewels through some contemporary notices at the finding and through the saved fragments. One of the most important pieces must have been the "big cross"-shrine with an alpha and omega pendants, from which remain two leaves from the covering in gold and precious stones, and one letter.

El Tesoro de Guarrazar fué descubierto casualmente a raiz de grandes lluvias tormentosas descargadas en Guadamur (distante $11 \mathrm{~km}$ de Toledo) a fines de Agosto de 1858. Había sido ocultado en dos hoyos o "cajas» revestidas de hormigón romano, que tenían una profundidad de $1,60 \mathrm{~m}$ y dejaban un hueco en cuadro de $0,75 \mathrm{~m}^{\prime}$. Cada uno de los depósitos tuvo un hallador distinto. Fué el primero Francisco Morales, labrador de 40 años, quien desarticuló muchas de las joyas, y vendió fragmentos y componentes en viajes frecuentes a los obradores de plateros toledanos. El francés $A$. Herouart,

1 Amador de los Rios, J., El arte latino-bizantino en España $y$ las coronas visigodas de Guarrazar. Madrid, 1861, p. 67. profesor en Toledo y amigo de Morales, adquirió las alhajas que éste aún tenia en su poder y se hizo con la tierra donde apareció el tesoro; en las excavaciones que ambos practicaron sólo descubrieron algunos colgantes y componentes menores arrastrados por las aguas. Herouart vendió las joyas al diamantista José Navarro, quien recompuso algunas de las coronas, rescatando lo que aún no habian fundido los plateros de Toledo. A comienzos de Enero de 1859, Navarro marcha a París y negocia la venta de las ocho coronas y seis cruces pendientes al Gobierno francés. El 2 de Febrero publican la adquisición diversas revistas galas.

El rápido eco de la noticia en España desató la intervención de la Comisión Provincial de Monumentos, primero, y la del Gobierno de la nación, después, que inició la rápida reclamación diplomática $^{2}$, una investigación judicial y excavaciones arqueológicas en el lugar.

El segundo lote sufrió también continuadas mermas por ventas de su descubridor, Domingo de la Cruz. En Marzo de 1861 acabó ofreciendo a la reina Isabel II las joyas que le quedaban, entre ellas la corona de Suintila.

Hoy, tras numerosos avatares, las joyas remanentes del Tesoro de Guarrazar se conservan en tres instituciones: El Museo de Cluny parisino guarda tres coronas ${ }^{3}$ (la de Sonnica [ $\mathrm{n}^{\circ} 153$ ], con cruz pendiente, otra decorada con arquillos $\left[n^{\circ} 155\right]$ y la ter-

2 Balmaseda Muncharaz, L. J., «La reclamación diplomática del Tesoro de Guarrazarm, en Boletin de $A N A B A D$, (en prensa).

${ }^{3}$ Caillet, J. P., L'antiquité classique, le haut moyen âge et Byzance au musée de Cluny. París, 1985, pp. 218-227. Los números son los de su catálogo. 
cera de reticula abalaustrada $\left[\mathrm{n}^{\circ} 154\right]$ ), una cruz colgante $\left[\mathrm{n}^{\circ} 156\right]$, la $\mathrm{R}$ pendiente de la corona de Recesvinto [ $\mathrm{n}^{\circ} 157$ ], que iniciaba el nombre del monarca, otros dos colgantes [ $\left.\mathrm{n}^{\circ} 160-161\right]$ y cuatro elementos de suspensión [ $\left.\mathrm{n}^{\circ} 158-159\right]$. En el Museo Arqueológico Nacional de Madrid se conservan las alhajas devueltas por Francia en $1941^{4}$, que son seis coronas (la de Recesvinto [ $\mathrm{n}^{\circ}$ inv.71202], dos de lámina de oro con decoración repujada $\left[\mathrm{n}^{\circ}\right.$ inv 71204 y 71205$]$ y tres de retícula abalaustrada $\left[\mathrm{n}^{\circ}\right.$ inv. 71206,71207 y 71208$]$ ) y cuatro cruces pendientes [ $\mathrm{n}^{\circ}$ inv. $71203,71209,71210$ y 71211$]$; además,el «brazo» de gran cruz [ $\mathrm{n}^{\circ}$ inv. 52561], el Alfa colgante y otros fragmentos y piedras sueltas [ $\mathrm{n}^{\circ}$ inv. 52560 y otros]. Finalmente en el Palacio Real de Madrid ${ }^{5}$ aún quedan, procedentes del segundo lote, la corona del abad Teodosio, la cruz del obispo Lucecio, una esmeralda grabada, además de pedrería y colgantes desprendidos. Un gran fragmento de corona de retícula y un florón con colgantes, de donde hubo de pender otra corona,desaparecieron en Octubre de 1936, igual que la corona de Suintila habia sido robada en $1921^{\circ}$.

La documentación procedente de la investigación judicial, conservada en el Archivo General de la Administración de Alcalá de Henares ${ }^{7}$, permite conocer nuevos datos sobre las circunstancias del descubrimiento, sus autores, $\mathrm{y}$ el destino que siguieron algunas de las joyas. La encuesta no resultó satisfactoria por las ocultaciones y mentiras de no pocos declarantes claves, la desconfianza ante el Juzgado y la premura con que éste actuó, presionado por el Ministerio de Fomento. En una primera parte (28-III/2-IV-1859), el Juzgado de $1^{\text {a }}$ Instancia de Toledo se constituye en Guadamur y toma declaración a los sujetos relacionados con el hallazgo; después (4 a 8-IV), ya en Toledo, declaran los plateros y testigos de las ventas. Tras recibir el expediente, el Ministerio de Fomento lo devuelve para que se amplíen algunos puntos $\mathrm{y}$, desde el 6-V al 7 VII, el

4 Museo Arquelógico Nacional. Guia General, v. II. Madrid, 1992 , pp. 53 y ss.

'López Serrano, M., «Arte visigodo: Arquitectura y escultura. Artes decorativas de la época visigoda. Adiciones", en Historia de España (dirigida por R. Menéndez Pidal), t. III. Madrid, $1963\left(2^{4}\right.$ ed.), pp. 768 y ss. Las joyas de Guarrazar estuvieron largos años conservadas en la Real Armería, después en una vitrina en la Biblioteca, y hoy se guardan seguras, fuera del circuito expositivo del Palacio.

'Lázaro, J., El robo de la Real Armeria y las coronas de Guarrazar. Madrid, 1925.

' Expediente Guarrazar. Sgn. 6571-1. Cfr. Ramos Ruiz, C., Catálogo de la documentación de Archivos, Bibliotecas y Museos Arqueológicos del Archivo del Ministerio de Educación Nacional. Madrid, 1950, p. 347.
Juzgado realiza nuevas actuaciones. En esta última fecha se remite toda la información a Madrid.

Para rastrear la cantidad y composición de las joyas que constituyen el tesoro perdido de Guarrazar, es preciso examinar las noticias de los declarantes en la encuesta, el fundamento de los rumores reflejados en los informes y el conjunto de los objetos completos y fragmentados que lograron rescatarse, en especial los del segundo lote. Advirtamos, como premisa, que la mayoria de las alhajas se hallaron enteras y no "en pedazos», como expresaron una y otra vez Morales y Herouart compinchados. Los descubridores, primero, hicieron el destrozo y desmontaje de muchas de aquellas, para llevarlas a vender a la ciudad; después, los propios joyeros, en casos concretos, consumarían la fundición de los fragmentos ofertados, según consta por sus declaraciones.

I. Los plateros que declaran son: José Gómez, Felipe Rodríguez, Mateo Gamero y Martín Vicente Velasco, todos con tienda abierta en la Calle Ancha de la ciudad, que entonces, como ahora, era su principal arteria comercial. ¿Qué compraron? ¿Qué joyas fundieron? En las respuestas a la doble pregunta se hallaría la clave para intentar una evaluación del tesoro perdido de Guarrazar. El Promotor Fiscal les cita "para que digan si han mercado alhaja alguna a algunos vecinos de la villa de Guadamur, especifiquen quién eran éstos, la clase de alhajas que les vendieron, su calidad y procedencia [...], precio que abonaron para su adquisición, dónde se encuentran estas» ${ }^{8}$. Las respuestas sólo admiten algún caso específico de compra, inducido por afirmaciones o citas de otros testigos.

1. José Gómez ${ }^{9}$ reconoce la adquisición de joyas a Manuela de la Cruz, ante el testimonio de ésta y otras dos personas que presenciaron la operación ${ }^{10}$. Manuela, hermana del segundo descubridor dice que encontró en el arroyo que atraviesa la villa de Guadamur "dos cadenas, al parecer de oro, y las que tenían cinco o seis piedras azules y blancas, y una de ellas la siguiente inicial $\mathrm{M}$, y también contenía piedrecitas muy pequeñas de color blanco como cristal». El 26 de Agosto se las presentan al tío Pepe, el sacristán (José Guillermo Sánchez), quien las describe como «una cadena de cuatro corazones de oro, cada uno de media onza, pesada por él, cuatro esmeraldas grandes engarzadas en oro, dicha cadena

\footnotetext{
Doc. de 4-IV-1859.

- Declaración de 5-IV-1859 ante el juez D. Fernando de la Cuadra.

${ }^{10}$ Decl. de 30-III-1859.
} 
tenia en medio una $M$ adornada de piedras preciosas como topacios y otras varias piedras preciosas. cuya clase no conocio, y otros pedazos de cadena igualmente adornados con piedras preciosas." Añade que sólo el oro tenia de peso de cinco a cineo y media onzas (150/165 grs.)". Mauricio Sánches. secretario del Ayuntamiento y primo de Manuela. a quien acompaño en el viaje de venta a Toledo, habla de euna cadena con eslabones con dos clavos. otra al parecer de metal dorado y varias piedras como topacios y zafiros" '2. Finalmente, Gomez dice que compró a Manuela «dos pedacitos de cadena de alambre de oro liso, de largo cada una como de unos cuatro dedos y el alambre, que era redondo. seria de grueso como un alfiler de los comunes, tres eslabones en figura de hoja de peral o corazon, también de oro. figurando la inicial $\mathrm{M} \dot{o} \mathrm{C}$. de la que penden tres zafiros taladrados por medio y, pasando por el taladro, un alfiler o ganchito de oro, y después tenia una perla que estaba pasada o muerta por el trascurso del tiempon. Cree que servirian para sostener algún adorno, collar o lámpara $y$, ante unos zafiros que le presenta el Juez como elementos comparativos, dice que los que compró eran de mayor color y en figura más almendrada ${ }^{17}$. Vicente Camarero, presbitero que presenció la venta, refiere que el platero quito varios cristales o piedras que tenian algunas de las alhajas; dos de éstas uparecian ser dos pedacitos de cadena de alambre y otra tiene como tres eslabones de los que colgaban las piedras, que por cierto eran azuladas y le parece tenian dos o tres granos de aljofar, que el platero aseguró estaba muerta y no tenia valor algunom ${ }^{14}$. Gómez pago por las joyas «veinte duros menos dos pesetas." Afirma que las fundió de nuevo empleándolas en el uso de su plateria.

El sacristán y Gómez describen con más precisión que los demás. Es claro que las alhajas, que Manuela presenta primero a aquel, han sufrido una cierta transformación antes de ser ofrecidas al platero: las dos cadenas se han convertido ahora en cuatro joyas separadas, los cuatro eslabones de hoja de peral son ahora tres, y las cuatro esmeraldas han desaparecido. Probablemente la jóven uniera los elementos diversos que vió el sacristan formando dos cadenas, y después,volvió a deshacerlos, restando y sumando otros, para vender en Toledo. Cuatro eslabones de hoja de peral tenian cada una de las cuatro cadenas que suspendian la corona de Suintila (frente a los cinco de la de Recesvinto), y es harto posi- ble que la otra corona, de la que sólo se conservaba parte de la crus colgante y la macolla que anudaba los suspensorios, tuviese identica estructura concatenal. Un vidrio verde o esmeralda engastado en capsula rectangular entra en la pedreria que remata cada letra colgante de las coronas de Suintila y Recesvinto, nunca van seriadas. La hipótesis resulta confirmada si se analiza la supesta letra M. que leyeron Manuela y el sacristán. Gómes admite la posibilidad de que fuese una $C$ y ello da la clave para interpretar la letra como una $\Omega$. cuyos brazos curvados hacia arriba y el pequeño entrante de la base hicieron dudar al platero. Formaria pareja con el $\Lambda$ conservado en el MAN. ( $n^{\circ}$ inv, 52560) [fig. 1], procedente del lote que se adquirio al diamantista $\mathrm{Na}$ varro, está hecha en lámina lisa de oro ribeteada de contario de minúsculas bolitas, con tres engastes de piedras preciosas. en el ángulo y en el final de las patas, respectivamente. La altura es de $5,3 \mathrm{~cm}$. y la anchura máxima de $4 \mathrm{~cm}$. El sacristán refiere que la letra que vió estaba adornada de piedras preciosas como topacios y otras varias. Todas las otras letras conocidas pendientes de las coronas tienen una misma composición, muy diferente de la que adoptan el $\mathrm{A}$ y la $\Omega$ : chapa de oro recortada, con los cantos en angulo hacia delante, formando como cajitas divi-

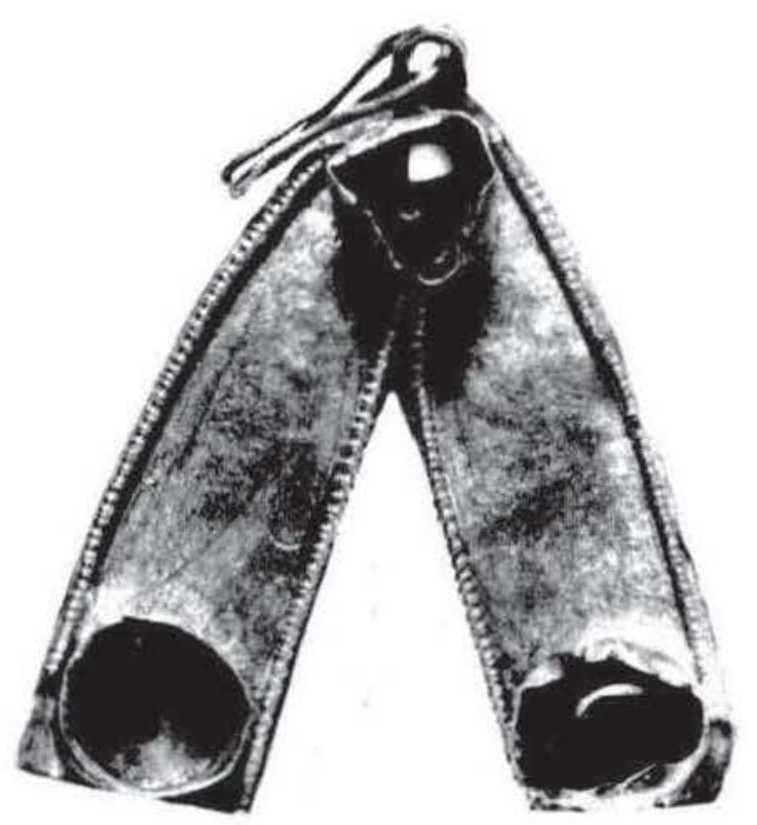

Figura 1. Colgante en forma de Alfa ( $\mathrm{N}^{\circ}$ Inv. 52.560). MAN. Madrid. 
didas interiormente por tabiquillos que dejan espacios triangulares habitados por granates o vidrios rojos. En contra del pareo de la omega con el alfa del MAN. estarían sólo aparentemente los pinjantes de la letra, que Gómez describe compuestos de tres zafiros taladrados, pasados por un ganchito de oro y después una perla. La combinación de zafiro rematando en perla es extraña, pues sistemáticamente los pinjantes siempre rematan en zafiro, amatista o piedra equivalente. Pero el alfa tambien debió tener pinjantes. En la zona inferior de la letra del MAN falta el ribete de bolitas encadenadas, denotando un corte en la delgada lámina; alli irian soldados los enganches de los pinjantes desaparecidos. Debieron ser muy pequeños los adornos pendientes, en proporción al tamaño de la letra. El presbitero $\mathrm{Ca}$ marero se aparta de la descripción de Gómez y parece dar a entender que las piedras azuladas colgaban de los tres eslabones (de hoja de peral) de una de las cadenas ${ }^{15}$.

La versión del hallazgo propalada por Manuela resultó poco creible e incluso su primo Mauricio declara que, en vez del arroyo del pueblo, fué en la Fuente de Guarrazar donde encontraría las joyas ${ }^{16}$. Es más verosimil que el conglomerado de joyas que Manuela manipuló formasen parte del lote hallado por su hermano Domingo y que aquella las sustrajese, haciendo creer que las había encontrado por su cuenta. El haber recurrido como acompañante para el viaje de la venta, no a su hermano, sino a un primo incrédulo a su relato, y los tardíos lamentos de Domingo de la Cruz de que «le hubiesen arrebatado algunas joyas, entregadas sin su consentimiento a los plateros de Toledo" ${ }^{17}$, avalan la deducción.

Fué la de Manuela, sin duda, una de las primeras ventas de objetos de Guarrazar en Toledo (según Camarero, en uno de los primeros ocho días de Septiembre ${ }^{18}$ ) y la más sonada. En sus declaraciones, se refieren a ella como conocida «de público» varios personajes de Guadamur. Contrasta con el sigilo y reserva que guiaron las intermitentes ventas de los descubridores en Toledo, que no lograron despertar la atención de los miembros de la Comisión de Monumentos.

2. Otro platero, Mateo Gamero, refiere ${ }^{19}$ que «en el més de Octubre se presentó un labrador de

\footnotetext{
15 Decl. de 5-IV-1859.

${ }_{16}$ Decl. de 30-III-1859.

17 Madrazo, P. de, «Orfebreria de época visigoda. Coronas y cruces del Tesoro de Guarrazar", en Monumentos Arquitectónicos de España. Madrid, 1879 , pp. 8 y ss.

is Decl. de 5-IV-1859.

19 Decl. de 5-IV-1859.
}

Guadamur en su tienda diciéndole si quería comprarle unos pedacitos de oro y un poco de plata. oxidada ya y en pedazos, que según éstos demostraban por su abuevación (sic) debían haber compuesto una especie de taza o vaso antiguo...los pedazos de oro formaban una especie de hojas de adorno los unos, otros una especie de cruz con engastes, pero ya sin piedras y tres trocitos de cadena de oro como de cuatro dedos, formadas en eslaboncitos" Los fragmentos de plata pesaron 24 onzas ( 720 gr.) y los de oro de 12 a 13 onzas ( $360 / 390$ gr.).Consigna que tanto el oro como la plata se hallaban con tierra, «por donde se infiere que habría estado todo enterrado». Lo compró todo en 3.000 reales y fué a parar al crisol de su establecimiento. Anota que la plata, fundida, mermó hasta unas doce o catorce onzas.

Los trozos de plata debían ser suficientemente grandes como para manifestar la curvatura envolvente (abuevación) que sugirió al platero la forma de taza o vaso. Por el peso del conjunto muy bien pudo tratarse de un cáliz. No conocemos ningún ejemplar de época visigoda, aunque los textos (conciliares y otros) citan el caliz con cierta frecuencia ${ }^{20}$. Con la carta que escribe el rey Recaredo al Papa S. Gregorio anunciándole su conversión, le envía un cáliz de oro, engastado su exterior en piedras pre$\operatorname{ciosas}^{21}$. En la época posterior mozárabe se citan en los inventarios de monasterios calices de oro con pedreria, pero la mayoría son de plata ${ }^{22}$. Desde antiguo, los cálices de plata revestían su interior de oro para hacerles inalterables al contacto con los elementos del vino. Menos verosímil parece la posibilidad de ser un recipiente de mayor tamaño, como los acetres litúrgicos, que se utilizan para trasportar el agua bendecida.

Fragmentos de plata oxidada, con decoración repujada de una figura se guardan en el MAN, ingresados con el lote de Navarro. Son minúsculos y no se puede apreciar curvatura alguna en su volúmen. Por el repujado de la decoración puede pensarse en láminas de aplicación que recubririan quizá algun recipiente. No creemos guarden relación con los trozos comprados por Gamero.

Las piezas de oro serían eslabones sueltos en forma de hoja de peral, correspondientes a una cade-

\footnotetext{
${ }^{20}$ Puertas Tricas, R., Iglesias hispánicas (siglos $1 \mathrm{r}$ al vili). Testimonios literarios. Madrid, 1975, pp. 95 y ss.

${ }^{21}$ Vives, J., Concilios visigóticos e hispanorromanos. Barcelona, 1963, p. 145.

${ }^{22}$ Cfr. Gómez-Moreno, M., Iglesias mozárabes. Arte español de los siglos $1 \times$ al $x I$. Madrid, 1919, p. 330. Cita otros de estaño o de marfil y quizás de vidrio.
} 
na de sujección de gran corona, y una cruz colgante de forma no común (expresión «especie de cruz»).

3. Finalmente el joyero Martín Vicente Velasco, citado en la declaración de su colega Felipe Rodriguez ${ }^{23}$, como adquirente de "varios pedazos de oro en figura circular, que eran sumamente antiguos", se escabulle afirmando que eran pedacitos de eslabones de una cadena de reloj y no denotaban antiguedad ${ }^{24}$. La posible conexión de la cadena con Guarrazar la sugirió Rodriguez por la época de la compra (Diciembre). Muchas de las cadenas suspensorias de las cruces pendientes y otras pequeñas coronas están formadas por eslabones circulares o por círculos alternando con otras piezas pequeñas en forma de 8 .

Hasta aquí lo que los plateros toledanos confiesan haber comprado. Pero debió ser mucho más. Domingo de la Cruz le confesaba a D. Antonio Flores, secretario de la Casa Real, que arrancaba de vez en cuando alguno de los colgantes de la coronas, "que vendia juntamente con otras piezas sueltas a los orifices toledanos" ${ }^{25}$. Ninguno de los joyeros cita a Morales ni a De la Cruz, que hubieron de ser muy conocidos por la frecuencia de las visitas. Aquel vendería en un lapso que abarca desde los últimos días de Agosto del 58 hasta fines de Septiembre o inicios de Octubre, tiempo en que pone el tema en manos de Herouart; y el segundo durante un período más largo, quizás hasta Marzo del 59, cuando, según la declaración de Francisco Pérez, los plateros «se negaron a verificar la última compra de alhajas que les ofrecieron los Cruces (Mariano y Domingo de la Cruz), temerosos de ser descubiertos por la autoridad superior de la provincia o por la Comisión de Monumentos Artísticos.» Esta institución habia comenzado sus actuaciones sobre el tema Guarrazar a fines de Febrero, y una órden del Gobernador civil al Alcalde de Guadamur (27-II) le conminaba a recoger cuantos objetos ya extraidos del terreno [de Guarrazar] o de los otros inmediatos, sepa existen en el pueblo, remitiéndolos inmediatamente a la Comisión de Monumentos por su conducto. Más tarde, el 10-IV, entre los acompañantes del Ministro de Fomento, que se desplazó a Guarrazar para constituir la Comisión de Excavaciones, figura un diamantista tasador del Monte de Piedad de Madrid, y aquel día se compra un lote de

\footnotetext{
23 Decl. de 5-IV-1859.

24 Decl. de 5-IV-1859.

2s Madrazo, P. de, o. c.. p. 8
}

restos de joyas presentados por vecinos de Guadamur, pagando por todo un montante de 998 reales $^{20}$. Hubo también viajes de los plateros toledanos a Guarrazar. Les guiaria su curiosidad ante el goteo de ofrecimientos, el propósito de salvaguardar la confidencialidad, y la certeza de que se trataba de un tesoro recientemente rescatado, como declaró Gamero al ver la tierra que acompañaba a las joyas. Consta el viaje de Gómez a Guadamur, a principios de Septiembre, si bien afirma que no consiguió entrevistarse con quien lo citó ${ }^{27}$. También Navarro viajó con Herouart a Guadamur.

Hay que suponer que los plateros no fundirian sus adquisiciones de modo instantáneo, sino según las necesidades de su comercio. Cuando Navarro decide adquirir a Herouart el lote de joyas que aún no habia vendido Morales, es porque ve posibilidades suficientes de reconstrucción a partir de lo que le ofrecen. Él y Herouart recorren por separado las joyerias toledanas recuperando los objetos de Guarrazar aún no devorados por el crisol $^{2 \times}$. La operación debió realizarse entre fines de Octubre y Diciembre, pues en los primeros dias de Enero del 59 Navarro ya está en Paris con sus joyas reconstruidas; acaso comenzase a fines de Septiembre, si nos atenemos a su afirmación. Mas, para evaluar lo recuperado en Toledo, es preciso averiguar el conjunto básico comprado a Herouart. En una carta al Ministro de Estado, en la que Navarro pretende justificar su actuación, exagera la fragmentación de las coronas; tan sólo los dos semicírculos de la de Recesvinto se hallaban completos, pero les habian arrancado todas las piedras, excepto un zafiro y cuatro o cinco perlas. "Los trozos de que se formaban las otras siete se hallaban tan dispersos que D. A. Herouart por su parte y yo por la mia hemos tenido que recorrer las platerias de Toledo para reunirlos. Ha habido letra que he hallado en tres trozos, rota, sin duda, con objeto de hacer saltar las piedras y pesar el oro. Quasi todo se ha hallado en el mismo estado. Por las últimas letras he dado cuanto se les ha antojado. Hay una pequeña cruz que da principio a la inscripción por la que querían un aderezo.» La hipérbole del diamantista es manifiesta si se constata el estado actual de las coronas. Dos de las de reticula abalaustrada y la decorada con arquillos en Cluny necesitaron los cuidados intensivos de Navarro; otras

\footnotetext{
${ }^{26}$ Documento del Ministerio de Fomento (Dir. Instrucción Pública) de 10-1V-1859, firmado por A. Fernández Guerra. Amador de los Ríos,J., op. cit., p. 62, notas I y 2.

27 Ampliación de declaración de 31-V-1859.

${ }^{2 k}$ Carta de Navarro al Ministro de Estado, de 15-III-1859.
} 
tres, reparaciones menores ${ }^{29}$. No es concebible que se embarcara en una empresa dineraria tan subida (72.400 reales le pagó a Herouart, según éste) sin tener entre manos los componentes esenciales de las coronas. $\mathrm{Y}$ aunque estuviesen privadas de pedreria, mucha de ésta debia hallarse en poder de Hérouart/Morales. El joyero Felipe Rodriguez declara que en Septiembre u Octubre Herouart le enseñó por amistad una cajita redonda de cartón conteniendo piedras de cristal, zafiros, amatistas, topacios, esmeraldas y perlas ${ }^{30}$. Algunas piedras, perlas y fragmentos de corona de retícula, fácilmente vendible por trozos, sí recuperarian el francés y Navarro; y sobre todo, los colgantes y elementos de suspensión de cadenas y cruces.

Reconoce en su declaración Felipe Rodríguez que Navarro se presentó en su establecimiento preguntándole si había comprado algunas alhajas antiguas o alguna parte de ellas, y su respuesta fué negati$v^{31}$. José Gómez, en cambio, silencia sus contactos con Navarro, pero los conocemos indirectamente por el testimonio del profesor de Instituto, Antonio Aquino, que acompañó a Amador de los Rios, comisionado por la R.Academia de la Historia, en sus pesquisas por la ciudad; dice que en casa del platero, Amador pidió le enseñase lo que tuviese procedente de Guarrazar. La respuesta fué que nada conservaba porque todo lo había vendido a Navarro, incluidos cuatro zafiros con los que pensaba hacer unos pendientes a su señora, accediendo a las repetidas instancias del diamantista; sin embargo le hizo a Amador unos dibujos de parte de las alhajas que compró $^{32}$.

No es aventurado pensar que si Morales no viajó a Madrid con Herouart para intentar vender las coronas a Navarro (aquel contestó negativamente ante el juez ${ }^{33}$ ), el viaje del francés y Navarro a Guada-

\footnotetext{
${ }^{24}$ Según Caillet (op. cit., pp. 218 y 222) las tres coronas hoy remanentes en Cluny hubieron de sufrir una nueva reparación entre la fecha de su adquisición (Febrero) y el 25 de Mayo del mismo año, según factura del restaurador. No se precisa el alcance de la intervención que pudo limitarse a resoldar elementos que se habian desunido. A la corona decorada con arquitos le colocó Navarro en el interior de la banda circular diez patillas de refuerzo, soldadas para consolidar los fragmentos del conjunto. Dos de las coronas de retícula abalaustrada del MAN. muestra numerosas soldaduras por su interior, $y$ una de las de chapa repujada cuenta con una lámina diagonal incrustada en su interior, que salva una rotura antigua.

Sobre la opinión de Navarro acerca de la composición de las alhajas que restauró, léase su carta al Ministro de Estado de 17-111-1859.

${ }^{30}$ Decl. de 5-V-1859.

${ }^{31}$ Decl. de 5-IV-1859.

32 Decl. de 5-IV-1859.

${ }^{33}$ Decl. de 30-III-1859.
}

mur tuviese por objeto asesorarse sobre la identidad de los establecimientos a los que vendió objetos Morales y sobre detalles de la forma primitiva que tenían las alhajas con suspensiones y colgantes más complicados. La descripción de las joyas, que hace el descubridor en sus declaraciones ${ }^{34}$, traduce una fina observación y larga contemplación de detalles.

Que algunas joyas de Guarrazar llegaron también al comercio de Madrid lo demuestra la tardia adquisición de unos fragmentos de cadena, de 51 y $20,6 \mathrm{~cm}$., constituidos por los típicos eslabones circulares alternando con otros en 8 . La compra se hizo, para el Museo de Cluny, el 6-VI-1864 a un tal Nicolas Jean, establecido en Madrid ${ }^{35}$.

II. 1. Herouart y Morales no vendieron todo a Navarro. Al menos aquel se reservó algunas piezas y entre ellas una corona, con las que pensaba negociar por su cuenta. El 22-VIII-1860, el francés escribe una carta al Ministro de Fomento sobre una "cruz coronada», que le había presentado días antes, a fin de que el Estado la adquiriese y conservase en un museo español ${ }^{36}$. Las negociaciones no dieron fruto y Herouart acabó enajenando al Museo de Cluny la novena corona (de retícula abalaustrada con cruz pendiente, C. $\mathrm{n}^{\circ} 154$ ), ingresada en Marzo de 1961. Acompañaban a la joya, dos eslabones de suspensión en forma de hoja de peral con un fragmento de cadena (C. $\left.\mathrm{n}^{\circ} 158\right)$ del mismo tipo que los adquiridos después a Nicolás Jean, un florón de suspensión, cuatro pequeños motivos en oro engasta-

\footnotetext{
34 Decl. de 30-III y $13-\mathrm{V}$ de 1859.

${ }^{35}$ Caillet, op. cit., $\mathrm{n}^{\circ}$ 159. No se sabe cómo llegaron las cadenas a manos de Nicolás. Acaso el primitivo posesor quiso vender anónimamente en la capital del reino para evitar posibles complicaciones que hallaria la venta en Toledo. $\mathrm{O}$ pudo ser $\mathrm{Ni}$ colás Jean uno de los numerosos agentes que compraban en España para importantes coleccionistas y museos europeos de la época. Vid. J.de D. de la Rada y J. de Malibrán, Memoria que presentan al Sr. Ministro de Fomento, dando cuenta de los trabajos practicados y adquisiciones hechas para el Museo Arqueológico Nacional, cumpliendo con la comisión que para ello les fué conferida. Madrid, 1871 , pp. 28 y 36. Los autores, comisionados por el Gobierno para la incautación de piezas con destino al MAN. toparon con algunos agentes en tierras castellanoleonesas.

El remanente del segundo lote del Tesoro habia sido donado a la Reina en Mayo de 1861.

36 Herouart habla de sus "comitentes», a los que intentará persuadir para que hagan amplias concesiones en el precio. No pasa de ser una argucia de trato comercial. Conocedores de las dctuaciones anteriores y de los rumores fantasiosos propalados por el francés, los miembros de la comisión, creada por el Ministro para dictaminar éste y otros asuntos, aconsejaron no ceder a las muy exageradas pretensiones económicas del vendedor. Cfr. Documento del Ministerio de Fomento (Dir. Instrucción Pública) de 20-XII-1860.
} 
dos de piedras y dos zafiros claros ${ }^{37}$. La cadena, el florón y las hojas de peral pueden aludir a alguna corona desaparecida.

2. En el MAN., aparte de las coronas y cruces regresadas de Francia, existe un conjunto de elementos sueltos, venido del Gabinete de Antigüedades de la Biblioteca Nacional, al constituirse el Museo. Está compuesto de tres lotes ${ }^{38}$, entre los que destaca el procedente de la venta de Navarro, que incluye el «brazo» de gran cruz, como pieza principal.

a) En realidad el llamado "brazo" ( $\mathrm{n}^{\circ}$ inv. 52561) [fig.2] son dos planchas de oro de $22 \mathrm{~cm}$. de anchura, por $10,5 \mathrm{~cm}$. de altura máxima en uno de sus extremos y $5 \mathrm{~cm}$. en el otro. Formaban parte de una cruz patada. Ambas haces tienen decoración menuda, calada, de roleos vegetales, sobre los que van ancladas, en cabujones de plato, piedras de varia especie, forma y tamaño, y perlas y nácares, todo dispuesto en formaciónes triangulares, unidas por ramos con hojas simétricas. Las planchas forrarian un alma de madera, pero ignoramos si eran anverso $\mathrm{y}$ reverso de un único brazo o, por el contrario formaban una de las caras de la cruz, que por el lado contrario tendría decoración distinta. La comparación con otras cruces semejantes en factura y época hace más creible la segunda hipótesis.

El primer documento que habla de su existencia es una anotación (de A. Fernández Guerra) en la que se hace balance de lo actuado por el Juzgado toledano y se aconseja una ampliación de la información fiscal sobre determinados puntos aún oscuros. El octavo era: «¿qué otros objetos halló o compró [Herouart] al Morales demás de las coronas?¿En poder de quién para el brazo de cruz grande de que ha dado razón Morales y las otras cruces descubiertas?» ${ }^{39}$. La instrucción reservada del 9-V-1859, procedente de la Fiscalía del Juzgado de $1^{\text {a }}$ Instancia

\footnotetext{
37 Según Caillet, op. cit., lo menudo no fué inventariado, pero es mencionado por P. Mérimée en un artículo en Le Moniteur Universel de 17-111-1861, recogido en P. Mérimée, Etudes sur les arts du Moyen Age. Paris,1967, pp. 271-274. El catálogo de Caillet no parece recoger el florón, los pequeños objetos de oro y los dos zafiros. Los pendeloques (C. 157, 160 y 161) pertenecieron a coronas devueltas a España.

is El primero lo forman los fragmentos de oro y pedreria adquiridos a vecinos de Guadamur, el 10-IV-1859, por el Ministro de Fomento, llegado al pueblo para constituir la Comisión de Excavaciones; el segundo abarca lo hallado por esta Comisión; el tercero comprende todo lo enajenado por José Navarro al Estado, a fines de 1860 .

${ }^{30}$ La anotación, sin fecha expresa, debió ser hecha entre el 8 IV, dia en que se envía el expediente a Madrid, y el 19-IV (del 1859), fecha en que el Ministerio se lo devuelve al Fiscal de Madrid. La R. O. comunicada por el M. de Fomento procediendo a la ampliación es de 29-IV-1859.
}

de Toledo, recibido ya de Madrid el diligenciado devuelto, establece las lineas de la pesquisa, los testigos que han de ser nuevamente interrogados y las preguntas a que se han de someter. Una de las preparadas para Herouart es la doble de la anotación de Fernández Guerra, pero en la segunda se omite la referencia a Morales ${ }^{40}$. Los plateros habian declarado el 5-V-1859. El 11 del mismo mes lo hace Herouart, pero, de las dieciseis preguntas que figuraban en la instrucción destinadas al francés, la única que no le formulan es ésta sobre el brazo de la cruz ${ }^{* 1}$. En Abril, pues, ya se sabia que la cruz habia sido destruida y tan sólo había sobrevivido «un brazo» de ella. Oficialmente el Juzgado no esclareció la identidad de su entonces posesor.

A comienzos de Julio del siguiente año, por gestiones conducidas quizá por D.A.Fernández Guerra a través de un amigo del platero Navarro, que era también "persona de la confianza del Gobierno», el diamantista presenta al Ministro de Fomento el fragmento de cruz con todo el lote de piedras y colgantes que aún tenía en su poder ${ }^{42}$. Una comisión se constituyó en el Ministerio para examinar la importancia de las joyas y la conveniencia y montante de la compra ${ }^{43}$. Reunida el 29-IX-1860, aconsejó la adquisición del conjunto $\mathrm{y}$, puesto que Navarro se habia negado a fijar precio, contentándose con lo que le diesen, cifró en 10.000 reales el pago razonable. En el documento, los comisionados refieren que «...es voz también de persona muy enterada de los objetos hallados en Guadamur ${ }^{44}$ que hay un báculo de oro y una cruz del propio metal completan[...]. Por último, dícese que el platero Gamero guarda de la misma procedencia «muchos objetos de oro del propio carácter eclesiástico [...] Estudiando el ex-

40 En las declaraciones de Morales ante el Juez, no hay referencia alguna al brazo de la cruz. O la confidencia se hizo en conversación privada,o acaso hubo una equivocación de informante.

4I A las preguntas que figuraban en el documento, el juez añade tres nuevas cuando Heouart es interrogado.

${ }^{42}$ Vid. el extenso documento del Ministerio de Fomento de 20-XII-1860, del que se reproducen algunos párrafos entrecomillados más abajo. El recibo de depósito del conjunto en el Ministerio está datado a $11-V 11-1860$.

43 Presidida por el Director General de Instrucción Pública, estaba formada por los Srs. Juan Eugenio Hartzembusch, José Caveda, Antonio Deigado, Francisco Bermúdez Sotomayor, José Godoy Alcántara, Aureliano Fernández Guerra y el platero Sr. Larra. La comisión dictaminó asimismo en contra de las pretensiones económicas de Herouart sobre la novena corona ofrecida en venta. Con anterioridad, Hartzembusch y Fernández Guerra habian intervenido decisivamente en la fijación de los versos de la lápida sepulcral de Crispin, consultados por la Comisión de Excavaciones.

44 Se alude a D. José Amador de los Ríos. 

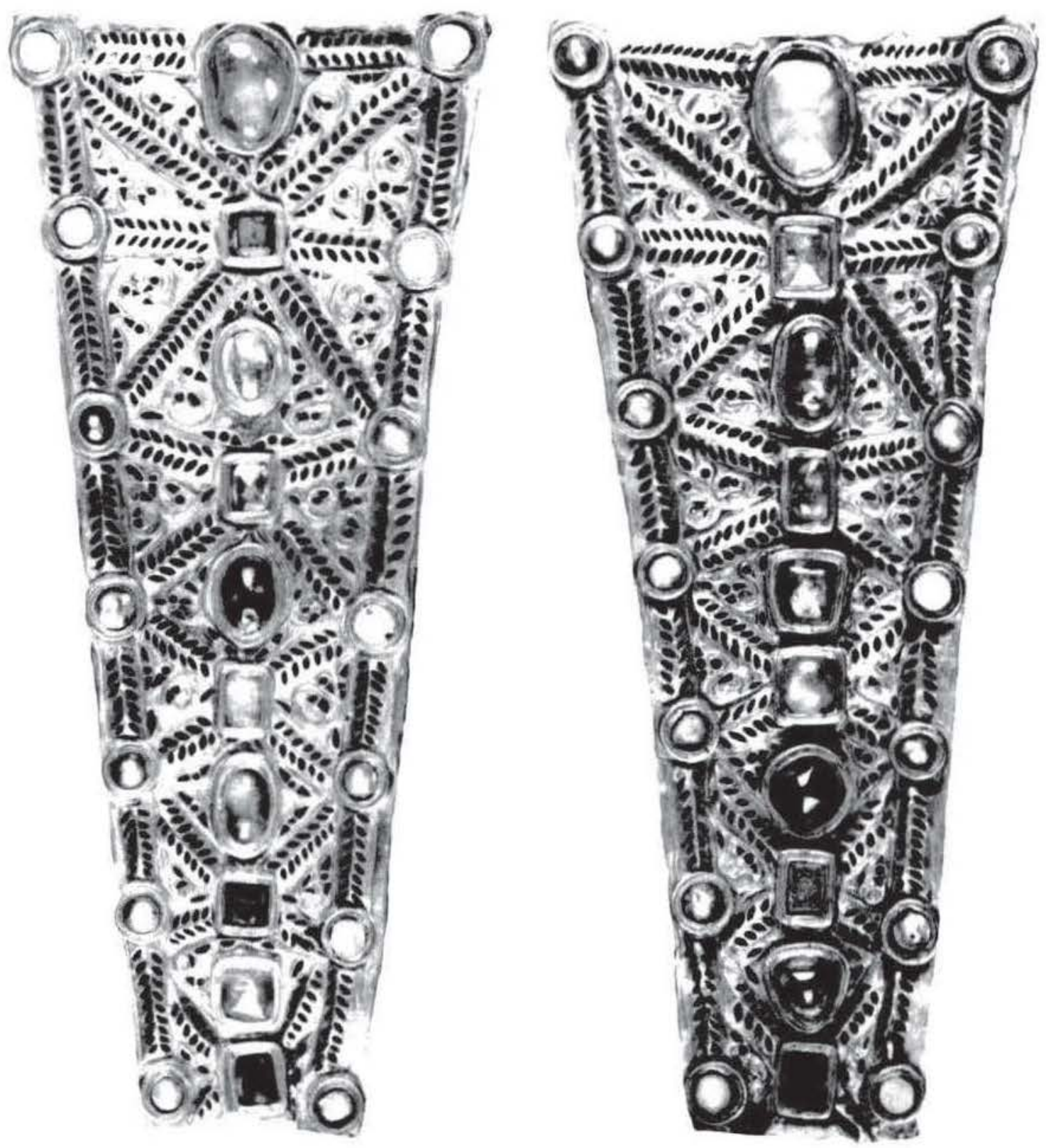

Figura 2. - Láminas de revestimiento de gran cruz ( $\mathrm{N}^{\circ}$ Inv. 52.565). MAN. Madrid.

pediente judicial y los fragmentos presentados en este Ministerio por el platero Navarro, calcula el Negociado que ellos fueron los primeros hallados por los vecinos de Guadamur; "[...] que dislocados los otros tres brazos de la cruz, llamaron la codicia de los inventores y estos, arrancando las piedras preciosas, machacaron el oro y le vendieron en Toledo. En el centro de la cruz debió haber un relicario y quizás los pedacillos de carbón sean reliquias...”

¿Cómo llegaron a Navarro los fragmentos de gran cruz? Una hipótesis creible es su compra a algún platero de Toledo. La conservación de los pedacitos de madera quemada (si admitimos su asociación con la cruz) parece indicativa de que el desmontaje de la parte o partes de la cruz fué obra, no del hallador, sino del joyero toledano; los «carbones» debieron estar en algún lugar señalado y eso les salvó de la destrucción. Navarro recibiría todo ya separado, como fragmentos dispersos procedentes de Guarrazar. Cuando él depositó las dos planchas de la cruz 
en el Minsterio. faltaban una perla y dos piedras en una de ellas ". No las habria extraido para emplearlas en la restauracion de las coronas, pues contaba con abundante pedreria suclta: sólo los zafiros incluidos en su lote ascendian a cuarenta y cinco. El diamantista, respetuoso en sus restauraciones ${ }^{\text {th }}$. parece haber conservado sustancialmente los haces de la crus como llegaron a sus manos.

Ya en el informe de la Comision se establece una acertada comparacion entre la cruz de Guarra/ar y la asturiana de los Angeles Lsta y otras cruces asturianas son cstudiadas modernamente por $\mathrm{H}$. Schlunk en una monografia que nos sirve de guia ". Las dimensiones de ambas debian ser muy parcias: Las maderas vertical y hori/ontal que soportaban las láminas de oro de la cruz asturiana ${ }^{4 x}$ median 46,5 y $45.0 \mathrm{~cm}$. mientras que las planchas de Guarra/ar alcanzaban los $22 \mathrm{~cm}$. cada una, a los que hay que sumar el pequeño espacio presumiblemente circular de la intersección de los brazos ${ }^{24}$. La de los Angeles tiene un disco central, que Schlunk considera de origen occidental, con paralelos italicos. Fl ensanche progresivo de los brazos hacia el exterior es

" "De cllas. la de mayor tamaño que tal ver Navarro deboo uttlear en la restauracion de las coronas, segun los huecos del cugasten, Vid Doc del Ministerio de Fomento de 20-XII-I860. Recoge no pocas conjeturas semejantes de los comismonados. pern una total ausencia de la información que pudiera haber aportade el mismo Navarro. Varios miembros de la Comision se entrevistafon con el para que fuara un precio al lote depositado y 10 consiguicron su proposito; en carta al Ministro, muy laconica. se realirma en su postura. Quizas no consideraron oportumo preguntarle of se nego a hablar del tema Su distanciamiento y displi. cencia de 1860 traduce una cierta amargura y contrasta con la colaboracion y explicaciones espontaneas que se leen en las dos cartas al Ministro de Fstado de 15 y $17-111-1859$ Acaso su salud ya no fuera buena, pues debio morir al poco tiempo: una carta de Herouart, fechada el 21-X11-1862. ya va dirigida a su viuda. Cor Alonso Revenga. P. A. Ilistoria det descuhrimiente del lessare visigodo de Guarrazar. Toledo, 1989. pp 58 y ss.

* Ilabia side cneargado, veinte antos antes, por la Real Acade. mia de la llistoria de restaurar el missorium de Teodosio, conservado en la Institución. Vid Delgado, A. Memoria hisforico-eritica sobre el gran disco de Teodesio encontrado en Almendratejo. Madrid. 1848. p. 12, donde se alaba su labor, hecha con los erilerios de la epoca. También se refiere al encargo el propio Navarro en su carta al Ministro de Estado de 15-111-1859

- Schlunk. H. Las crues de Oviede. El culto de la vera cruen el reine asturiano. Oviedo, 1985 $\mathrm{E}$ I estudio se abre con uma recopilación de testimonios epigraficos y literarios sobre la gran veneración de la eruz en época visigoda.

"Destruida a raiz del robo de 1977

* Una de las planchas dibuja en su extremo mas corto una leve curvatura cóncava, que falı en la otra. Pero una anotación de Amador de los Rios puede infundir sospecha de alguna falta en la integridad de las piezas en los extremos cortos. En $\sigma . c$. p. 132, n"2, refiere que algunas de las laminillas del brazo de la cruz sirvió para someterlas a analisis quimicos que determinasen el grado de pureza del oro. La muestra (o muestras) hubo de recortarse de ese sector. único que no tiene rebordes. menor en la crue asturiana que en la de Giarrazar Otra cierta similitud se muestra en la decoracion del anverso de la cru/ asturiana, enriquecido con cuarenta y ocho piedras preciosas en cabujones de plato. de los que die/ se alojaban en cada brazo y cabecera. nueve en los pies, además de otros nueve en el disco. En la cruz toledana van diez piedras en la linea central de cada plancha. igualmente en cabujones. flanqueados por siete perlas o nacares arriba y abajo. enlazados por cadenctas caladas. I a disposicion de las capsulas dificre, como tambien el fondo sobre el que se asientan. totalmente cubierto de filigrana en el anverso de la asturiana. $y$ de unos verdugones de roleos vegetales y ramos calados en la de Ginarrazar. Algunas de las piedras de la joya de los Angeles son camafeos romanos, ausentes en la toledana: pero. entre los zafiros sueltos ingresados en el lote de Navarro hay uno que es un entalle romano, con cl busto de un varón togado [fig. 3].

Por el reverso la cru/ asturiana posec una inscripcion dedicatoria sobre lamina de oro, lisa en gran parte. Los bordes de la joya se remataban mediante una sucesión de perlas de oro enfiladas, como sucede en muchas de las alhajas de Guarra/ar; como ejemplo más cercano puede traerse el "alfa" colgante del MAN., que se finaliza de igual forma.

La asturiana era una cruz-relicario, segun to demuestran los receptáculos con tapa corredera excavados en la parte más ancha de los brazos y en la cabecera. Tenia también tres ojetes en el borde inferior de cada brazo, donde irian anclados, según Schlunk, colgantes al estilo de los que exhiben las pequeñas cruces de Guarrazar. EI sabio germano descarta la opinión de Amador de los Rios, quien sostenia que la cruz habria tenido pendientes el alfa

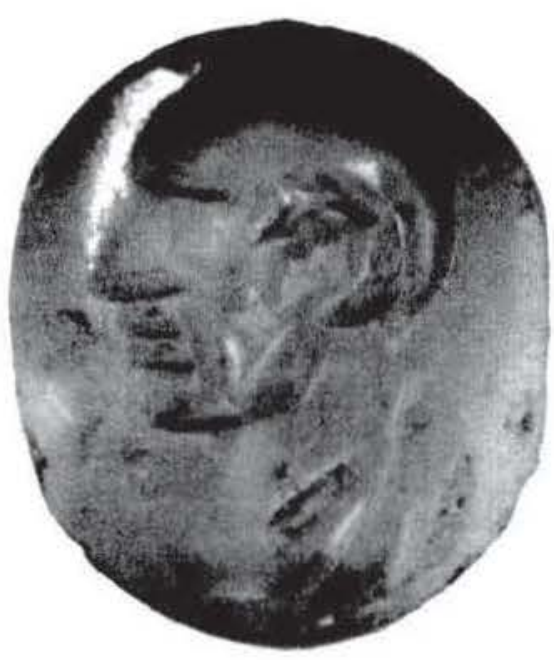

Figura 3. Zafiro grabado con busto varonil ( $\mathrm{N}^{\circ} \ln \mathrm{n}$. 1995/74/19). MAN. Madrid. 
y la omega, clásicas ya en el mundo visigodo. Según áquel, la de los Angeles no era una cruz procesional estricta, sino que se guardaria en el tesoro de la catedral para ser llevada precediendo al obispo en ocasiones solemnes ${ }^{50}$.

La asociación del «alfa» del MAN. ( $\mathrm{n}^{\circ}$ inv. 52560) y de la «omega» vendida por $\mathrm{M}$. de la Cruz en Toledo, a la cruz de Guarrazar parece de todo punto correcta; su tamaño y decoración con cabujones concuerdan con la pieza toledana. El propio Schlunk recuerda la raigambre de las letras en las cruces altomedievales de occidente y, sobre todo, en el ámbito visigodo a partir de la abjuración de arrianismo, como proclamación simbólica de la consubstancialidad divina del Hijo, que aquella herejía negaba ${ }^{51}$.

Nos inclinamos a considerar las planchas del MAN. como el anverso de los brazos de la cruz y no el revestimiento de ambas caras de un sólo brazo. Es dificil concebir que una cruz de proporciones, materia y decoración semejantes careciese de inscripción dedicatoria, ostentándola en el reverso otras más modestas y pequeñas del mismo Tesoro. La decoración calada de roleos vegetales y ramos es muy igual a la que corre por la banda central de la corona de Recesvinto, de la que penden, en su base, las letras que proclaman la ofrenda del rey.

Respecto a los "carbones», la sugerencia de los miembros de la comisión de compra no parece descaminada, pues si no son reliquias ¿por qué se han conservado? ${ }^{52}$ De aceptar la opinión de los comisionados, ignoramos en qué parte de la cruz estarían alojados los fragmentos de madera. Ya se ha aludido a los receptáculos de la cruz de los Angeles; Schlunk recuerda que la intersección de los brazos de la cruz siempre se consideró lugar privilegiado para guardarlas, pues fué alli donde reclinó su cabeza el Señor ${ }^{53}$.

b) En el lote de Navarro se incluían unos fragmentos de lámina de plata decorados en repujado, a los que antes se aludió ( $\mathrm{n}^{\circ}$ inv. 62168) [fig. 4]. En la relación firmada por $\mathrm{A}$. Fernández Guerra ${ }^{54}$ figuran bajo el $n^{\circ} 2$ como "dos pedazos de plata oxidada que presentan la cabeza y los ropajes como de un ángel. Son pequeños y los acompañan otros varios

\footnotetext{
so Schlunk, H., op. cit., p. 23.

si Schlunk, H., op. cit., pp. 26 y ss.

52 Sería conveniente efectuar un análisis para determinar el tipo de madera y poder comparar sus resultados con otros que se hayan hecho a reliquias de la Vera-Cruz. Sobre reliquias de la Vera-Cruz en la Hispania visigoda, cfr. Schlunk, H., op. cit. pp. 9 y $\mathbf{s s .}$

s3 Schlunk, H., op. cit., p. 24.

34 Doc. Ministerio de Fomento de 20-XII- 1860.
}

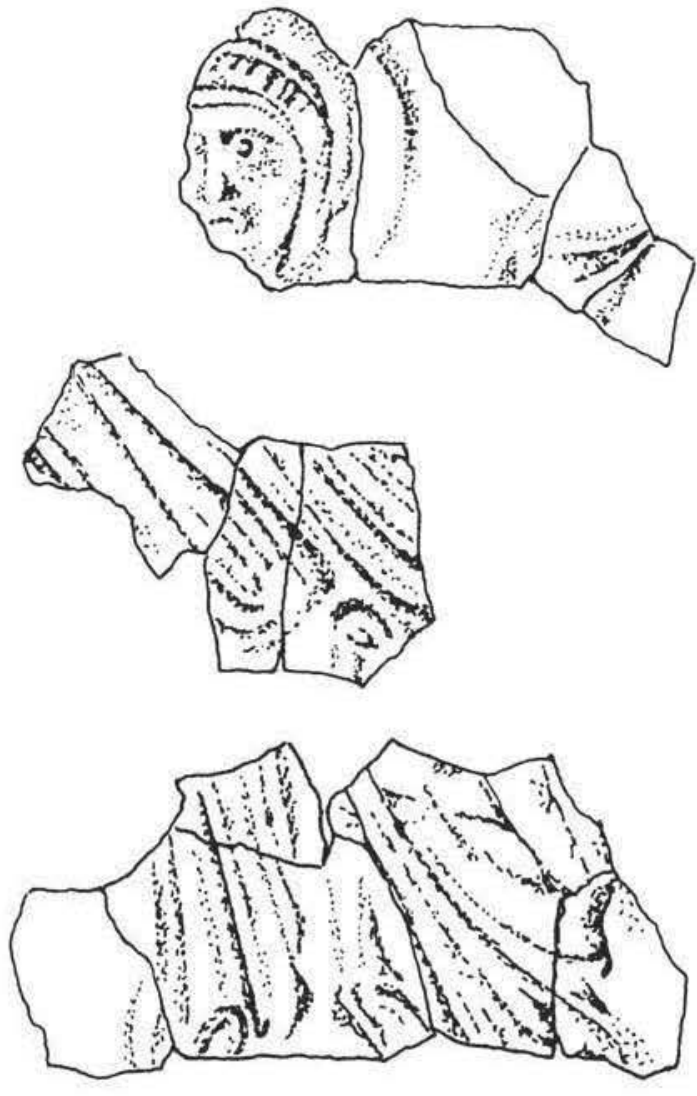

Figura 4.-Figura femenil que decora los fragmentos de láminas de plata ( $\mathrm{N}^{\circ}$ Inv. 52.509/16). MAN. Madrid. Dibujo de Fernando Fernández.

sumamente diminutos». Recientemente han sido limpiados, y unidos algunos de ellos ${ }^{55}$, pero su oxidación ha deteriorado la superficie del anverso y la decoración se aprecia con dificultad. Compónese ésta de una figura, al parecer femenil, su cabeza velada o nimbada y su túnica con profusos pliegues. La postura, sedente o en pié, no aparece clara y unos rasgos en la zona derecha, a la altura del rostro, pueden ser interpretados como la palma de la mano extendida o parte de un ala. ¿Es una Virgen?, ¿una orante?, ¿un ángel? La figura posee un cierto resabio clásico común a muchas del arte paleocristiano. En el ámbito visigodo no recordamos paralelos cercanos; la Anunciación del entalle de la esmeralda, procedente de Guarrazar, y los personajes plasmados en escultura arquitectónica presentan una estética diferente. Tan sólo la Virgen de la fibula circu-

ss Por D. Antonio Sánchez Barriga, Restaurador del MAN, hoy en el ICRBC. 
lar de Turuñuelo (Badajoz), hoy en el MAN., parece prestarse a cierta similitud, causada quizás por el repujado en metal de ambas piezas. No hay datos para averiguar si el personaje estaba aislado o formabi parte de una escena más amplia.

Por la decoración repujada, los fragmentos de plata hubieron de ser acaso el revestimiento de algún recipiente o cajita de madera u otro metal menos noble. No hay horadamientos para los clavitos de sujección en los minúsculos restos conservados; la lámina bien pudiera ir incrustada mediante un enmarcamiento. El catálogo que hace $\mathrm{H}$. Buschhausen ${ }^{56}$ de los relicarios paleocristianos recoge numerosas figuras de orantes parecidas.

c) La mayor parte de la copiosa pedreria suelta (zafiros, esmeraldas, cristales de roca, vidrios, perlas, cuentas de oro, etc.) procede del lote de Navarro, adquirida por él a Herouart/Morales y a los plateros toledanos. Hay un par de colgantes iguales a los que ostentan cruces y coronas ( $\mathrm{n}^{\circ}$ inv. 52563 y 52564), que pudieron pertenecer a alguna joya perdida. Un tercero, menor, y dos fragmentos de cadena de eslabones circulares y en 8 , son lo más significativo.

3. Resta examinar el conjunto conservado en el Palacio Real de Madrid, constituido por las joyas que, tras frecuentes enajenaciones, aún permanecian en poder de Domingo de la Cruz. Pasaron a propiedad de la Corona por la ofrenda que de ellas hizo éste a la reina Isabel II, en Mayo de 1861 .

Era sabido en Guadamur que Domingo y su hermano «se habian encontrado varias alhajas en los terrenos del primer descubrimiento" y que habian vendido en Toledo ${ }^{57}$. No pudieron ocultar el hecho, aunque si la magnitud del hallazgo. La investigación judicial centró sus pesquisas en Herouart y Morales principalmente, porque ellos habian sido el origen de la emigración de las coronas a Francia. Mas, desde el planteamiento inicial se pensó en que Domingo fuera interrogado ${ }^{58}$. La contestación que

\footnotetext{
st Buschhausen, H., Die spätrömischen Metallscrinia und frühchristlichen Reliquiare. 1. Teil. Katalog. Wien, 1971, $\mathrm{n}^{\circ}$ A64, A66, B4, B5, etc.

57 Francisco Pérez, teniente alcalde de la villa, en decl. de 31-III-1859, afirma que Herouart se lo aseguró en conversación privada. Los De la Cruz tenian una tierra lindante con las Huertas de Guarrazar.

"Vid. el doc. del M. de Fomento de 24-III-1859, encabezado como Instrucción reservada para el Promotor Fiscal de To. ledo, en orden a la información que se le manda hacer de orden de $S . M$. «Deberán asimismo ser interrogados Domingo de la Cruz y D. Mauricio Sánchez sobre el dia o tiempo en que adquirieron varios objetos y si los hallaron por sí o cómo los hallaron. A primero convendria interrogarle sobre el dia en que llevó a Toledo objetos del hallazgo para venderlos y a quién los vendión.
}

da al juez en su declaración de 30-III-1859 es tajante: "Que jamás se ha encontrado alhajas u objetos preciosos y de consiguiente no los llevó a vender a Toledo ni a ningún punton " 54 . Las ventas frecuentes en Toledo, confesadas por él más tarde, debieron producirse con discreción, y los plateros en sus declaraciones no le descubrieron. Después, ante la dificultad de dar salida a sus joyas, optó por obsequiar dos de ellas a la Reina ${ }^{(1)}$. Fué D. Antonio Flores, ilustre periodista y secretario de intendencia de la Casa Real, quien, instigado por la soberana, se ganó la confianza del Domingo y, en Guadamur supo persuadirle de que donara todo lo que escondia. Al Sr. Flores debemos las declaraciones que le arrancó al segundo descubridor del Tesoro, transmitidas por J. Amador de los Ríos, J. de D. de la Rada y Delgado y P. de Madrazo, primeros observadores y estudiosos del conjunto de la Armería. Refiere Madrazo que Domingo de la Cruz unoticioso del hallazgo de sus convecinos, lograba la dicha de tropezar con el segundo depósito, contiguo al primero y aún intacto. Sacó de él, si hemos de atenernos a su dicho. unos como cinturones de oro y pedrería y una grande y magnifica corona, otras coronas lisas y pequeñas, varias cruces de chapa sencilla y muchos objetos diminutos de ignorado uso. Llevólo todo a su casa, metiólo en unas ollas de barro que tuvo escondidas con gran secreto. No se determinó a hacer pedazos las coronas; limitóse a arrancar de vez en cuando algunos de sus arambeles, que vendia juntamente con las otras piezas sueltas a los orifices toledanos. [...] Mostróse pesaroso de haber destruido otras muchas joyas, no sin dolerse de que le hubieran arrebatado algunas, entregadas sin su consentimiento a los plateros de Toledo y refirió al Sr. Flores que entre las alhajas habia unas que llamaba cinchos de oro $y$ piedras preciosas, que serían tal vez talabartes o cinturones o acaso diademas; $y$ una paloma de oro que probablemente fué una pixis sacra o vaso eucaristicon. ${ }^{\circ}$

La narración de Domingo de la Cruz, contradic-

\footnotetext{
s4 Más tarde, el 21-V-1859, Herouart contesta a preguntas del juez que "conoce al sujeto que se le cita [Antonio de la Cruz] y sabe que él o su familia se habian encontrado también algunas alhajas, ignorando de qué clase son éstas». Pese a ello, Domingo no es reinterrogado.

* La corona del abad Teodosio y la cruz de Lucecio. En la decisión influyó su tío Juan, maestro de Guadamur, que le acompañó a Aranjuez para presentar las alhajas a la Reina.

A1 Madrazo, P. de, op. cit., p. 8; Amador de los Rios, J., op. cit. p. 109: «Mostrábase el Cruz pesaroso de haber destruido otras muchas joyas, no sin dolerse de que le hubieran arrebatado algunas, entregadas sin su consentimiento al brazo seglar de los plateros. Las informaciones de D. Antonio Flores, conformes en todo a las noticias recogidas por nosotros en la primera investigación, justificaban las palabras del arrepentido labriego...».
} 
toria en aspectos, dada a la imprenta por Madrazo, ha acompañado casi todas las reseñas del Tesoro de Guarrazar magnificando su volúmen y variedad y lamentando su parcial destrucción.

Más segura información suministra el mermadisimo conjunto del Palacio Real, hoy compuesto por la corona del abad Teodosio, la cruz de Lucecio, una esmeralda con entalle de la Anunciación, y la pedrería y colgantes sueltos de rigor.

a) La corona de Suintila ( $\mathrm{n}^{\circ}$ inv. 2638), joya principal del lote (y acaso del conjunto del Tesoro) fué robada de la Armeria de Palacio en 1921 y no se ha vuelto a saber de ella ${ }^{62}$. Era la más antigua; existen buenos estudios, dibujos y fotografías, pero, por desaparecida, conviene apuntar una breve descripción. Compuesta por dos chapas dobles de oro, semicirculares, articuladas mediante bisagras, de $6 \mathrm{~cm}$. de altura, que forman un diámetro de $22 \mathrm{~cm}$. Lisa la interior, tiene la externa en sus bordes dos aros sobremontados, algo más resaltado el de abajo. La banda media se decora con fila de grandes rosetas de ocho pétalos, encerradas en círculos tangentes, con una perla o un zafiro (alternados) alojados en receptáculos en el centro de cada una de aquellas. También los aros superior e inferior aparecen cuajados de una sucesión de zafiros cabujones y perlas. De unos pequeños ojetes, que nacen del borde inferior, cuelgan las cadenitas que sostienen las letras componedoras de la inscripción +SVINTHILANVS REX OFFERET, en forma y estructura semejantes a las de la corona de Recesvinto. Sólo sobrevivían doce más la crucecita inicial. A cada letra suceden una capsulita cuadrada conteniendo una piedra o vidrio, una perla, una cuentecilla de oro y, rematando, un grueso zafiro. De cuatro anillas soldadas al borde superior de la banda arrancan las cuatro cadenas, compuestas por cuatro eslabones en forma de hoja de peral calada, con el vértice arriba. Las cadenas se reúnen en un florón formado por dos azucenas, contrapuestas a una bola achatada y facetada de cristal de roca. De los seis pétalos de cada azucena cuelgan pinjantes constituidos por un cono de oro, una perla y un zafiro o amatista.

Una cadena con eslabones circulares y de ocho alternados sostiene la cruz desde la base del florón. Formada por los fragmentos de dos cruces idénticas $^{63}$, muestra, tras el ensamblaje, un medallón cir-

\footnotetext{
${ }^{62}$ Vid. Lázaro, J., op. cit.

${ }^{63}$ Refiere Madrazo, op. cit., p. 34, $\mathrm{n}^{\circ} 1$, que cada uno de los dos fragmentos se componía de dos aspas y el medallón central y que no siendo posible restaurar las dos cruces, se acordó sacrificar uno de los medallones y hacer una sóla cruz, si bien ésta resulto incompleta.
}

cular central que, en una de las caras, lleva alojado un zafiro, y en la otra, un cristal de roca, rodeados de una corona de perlas alternadas con cuentas de oro. Del medallón parten cuatro tallos, cada uno de los cuales, en complicado diseño, se divide en dos revolviéndose hacia dentro y dando orígen luego a otros dos que, siguiendo direcciones oblicuas, se bifurcan y revuelven nuevamente. Los tallos se adornan con incisiones y caladuras en las que se dejaban ver granates, y un zafiro cabujón (en los cuatro primeros tallos) o perla (en los ocho vástagos extremos) señala cada intersección. Los espacios resultantes revisten forma de palmeta bizantina con el vértice hacia el medallón central. De los vástagos más inferiores cuelgan sendos pinjantes.

b) Habia también un florón de suspensión $\left(\mathrm{n}^{\circ}\right.$ inv. 2643) de otra corona desaparecida, de composición análoga a la de la ofrenda de Suintila; la bola de cristal de roca es aquí más aplastada. Los pinjantes de los pétalos de la azucena inferior tienen un zafiro excesivamente grueso, que resulta discordante si aplicamos los parámetros estéticos de las coronas de Suintila y Recesvinto.

El florón y la doble cruz pendiente denuncian la existencia en el lote de Domingo de otra corona, cuya soberbia factura debia ser semejante a la de Suintila, ofrenda probable de otro monarca.

c) Que el segundo depósito contenía asímismo coronas de retícula abalaustrada lo demuestra el gran fragmento ( $\mathrm{n}^{\circ}$ inv.2642) de una de ellas (en realidad media corona), desaparecido junto con el florón anterior, «en los trastornos sufridos por el Palacio de Oriente en otoño de $1936 »{ }^{64}$. Compuesto por tres filas de balaustres horizontales y seis verticales, que dejan 5 mallas o espacios libres arriba y otros tantos abajo. Faltan tres clamasterios en la parte que se conservaba. Se colgaba abierta en amplio semicírculo mediante dos alambres anclados en los extremos.

d) La esmeralda sin pulir, grabada con la escena de la Anunciación, mide $2 \times 1,5 \mathrm{~cm}$. Su cara principal presenta dos facetas donde aparecen los dos personajes sacros. Debió estar engastada en alguna joya perdida «mediante un perno que penetraba en ella y cuya señal es visible» ${ }^{65}$.

f) Unos fragmentos de perlas, piedras sueltas y algún pinjante completan lo entregado por Domingo de la Cruz.

La adquisición de los restos del segundo lote puso

\footnotetext{
bópez Serrano, M., op. cit., p. 769.

os Madrazo, P., de, op. cit., p. 66. El agujero es bien visible en la parte superior y se aprecia con mayor dificultad en la inferior por causa del enmarcamiento que la rodea.
} 
en evidencia que los objetos habian sido hallados completos y que lo mismo habia que deducir para lo descubierto por Morales. El cambio de dueño permitió detener, como en una instantánea, un proceso de descomposición de las alhajas, llevado a cabo durante cerca de tres años por el Cruz. Habia piezas integras, otras que comenzaban su desintegración perdiendo los pinjantes (corona de Suintila); algunas se hallaban demediadas (corona de retícula), otras, desaparecidas, habian dejado algún testigo de su ser (florón y fragmento de cruz colgante; esmeralda). Y otras, en fin, de cuya existencia sólo sabemos si aceptamos la confesión de su descubridor y destructor.

Asímismo, el conocimiento detallado de las nuevas joyas que contaban con sus aderezos íntegros disipó las dudas, que algunos insinuaban, sobre la autenticidad del conjunto de Cluny y permitió un cotejo con las restauraciones efectuadas por Navarro. En la corona y cruz de Suintila las piedras estan colocadas cuidadosamente alternando zafiros y perlas, o éstas con cuentas de oro, etc., detalle, que el diamantista no supo o pudo imitar.

Salvo matices como éste, la labor de Navarro en una corona tan complicada como la de Recesvinto se apreció meritoria; únicamente la disposición de las letras colgantes, que reunió, estaba carente de sentido.

III. Los dos hoyos que contenían el Tesoro de Guarrazar eran de dimensiones y capacidad semejantes. Nueve coronas y seis cruces, con sus respectivas cadenas y colgantes, que componian el primer conjunto (Morales/Herouart), cabían sobradamente en uno de los escondrijos y aún quedaba amplísimo márgen para las piezas destruidas. El segundo lote, muy aminorado, estaba formado por al menos cuatro coronas (incluida aquella de la que sólo restaban el floron y parte de la cruz colgante), tres cruces y posiblemente la gran cruz de la que se guardan partes en el MAN. Si postulamos un cierto equilibrio entre el volúmen de ambos conjuntos, queda espacio para admitir el relato de Domingo de la Cruz; los «cinchos» de oro y pedrería (al menos dos) y la paloma de oro y piedras finas, de tamaño natural debieron salir del segundo escondite.

D. José Amador de los Ríos, que pasó largos días en Guadamur, dirigiendo las excavaciones ordenadas por el M. de Fomento, y en Toledo, recabando información de los plateros, confirma que tanto éstos como los labriegos de aquella villa hablaban de la paloma ${ }^{66}$ y la describian descansando en una peana

os Amador de los Ríos, J., op. cit., p. 124. En n 4 transmite la confidencia de una persona entendida y conocedora del asunto, de que esta paloma habia sido arrojada al Tajo por el platero también de oro adornado de labores. Juzga el sabio profesor con acierto que la joya se destinaría a la custodia de la Eucaristía. Recipientes o vasos sacros en forma de paloma empleados para tal fín son conocidos por textos literarios desde el siglo III. $\mathrm{H}$. Leclercq $^{67}$ cita a Tertuliano y a S. Juan Crisóstomo y demuestra que su uso se prolongó al menos hasta el final del siglo vı, por un texto de Gregorio de Tours, quien refiere de un miembro del ejército del rey Sigeberto que penetró en la basílica de SaintDenis para saquearla e intentando destruir una paloma de oro con su lanza, erró el golpe y encontró la muerte. También servian como depósito del oleo sagrado para la unción bautismal en muchos baptisterios.

Se lamenta Leclercq de que ningún ejemplar antiguo de tales palomas haya llegado hasta nosotros, pero lo explica por el alto valor material de estos objetos, fáciles de robar y fundir.

Enumera también Amador entre los objetos perdidos «diferentes cingulos o bálteos y algunos coIlares»" ${ }^{6 x}$. Aquellos serian los "cinchos» que Domingo refírió al Sr. Flores había él destruido. Tales joyas pudieron tener un carácter militar, como prendas del traje real, herederas de los «cingula militiae» tardorromanos, muy conocidos en numerosos ejemplares ${ }^{69}$. Tenían carácter de insignia oficial, símbolo del rango de quien lo portaba. Los emperadores y personajes consulares vestidos a la moda bizantina acostumbran llevar cinturones de oro y gemas. En un medallón de oro de Valente y Valentiniano aparecen ambos príncipes adornados cada uno con un ámplio cinturón gemado, en el que va prendido delante un adorno en forma de "bulla» ${ }^{70}$. Es seguro que en la corte visigoda, muy influenciada por la

que la adquirió, temeroso de represalias por el eco en la prensa de la indignación patriótica que la venta en Francia habia originado, $\mathrm{y}$ añade: "algún tiempo después se nos dieron nuevos avisos de que realmente existia la paloma y la misma especie ha traido de Toledo el Sr. Flores..." C fr. también Madrazo, P. de, op. cit., p. 49. Pero nótese que la obra de Amador es dieciocho años anterior al escrito de Madrazo.

"7 Leclercq, H., en DACL., s.v. "Colombe Eucharistique». Un pasaje de la Vida de S. Basilio, atribuida a Amfiloque, refiere que el santo, «habiendo llamado a un orfebre, le encargó hacer una paloma de oro puro en la que depositó una porción del Cuerpo de Cristo y la suspendió encima del altar santo como una figura de la paloma sagrada que apareció en el Jordán, encima del Señor, en su bautismo".

"* Amador de los Rios, J., op. cit., p. 124.

${ }^{69}$ Eran de cuero recubiertos por una serie de plaquetas de metal con adornos calados o en relieve. Un estudio reciente sobre algunos de Hispania es el de Pérez Rodriguez-Aragón, F., "Los cingula militiae tardorromanos de la Peninsula Ibérica", en BSAA. U. de Valladolid, LVIII (1992), pp. 239-262. Cfr. también Floriani Squarciapino, M., en $E A A, 11$, s.v. "Cinturone".

${ }^{7} \mathrm{C} f r$. Leclecq, H., en $D A C L$., s.v. "Ceinture". 
pompa bizantina, desde Leovigildo, se usaron semejantes cinturones en ceremonias señaladas. El «balteus» era propiamente el tahali o talabarte que, llevado en banderola, servía de soporte a la espada. En el Bajo Imperio habia ejemplares ricamente enjoyados. Pero también había cingulos de oro litúrgicos: Leclercq aporta una cita de un texto del siglo vili en el que se menciona, entre los vasos sagrados y las vestiduras preciosas, un cinturón gemado y perlado que el sacerdote usaba cuando celebraba la Misa ${ }^{71}$. Y Amador recuerda que en el 943, el obispo de Dumio, Rudesindo, donó al monasterio de Celanova dos cíngulos de oro cuajados de pedrería y otros varios de plata, uno de los cuales era gemado ${ }^{72}$. Parece más aceptable para el caso de Guarrazar la ofrenda regia de una prenda señalada y de alto valor material y simbólico, en clara consonancia con corona y cruz. Que las donaciones reales posteriores incluían tales elementos, lo demuestra la de Ordoño $I$, que ofrece ante el altar de Santiago del monasterio de Sobrado un conjunto de joyas, entre las que habia un bálteo ornado con piedras preciosas ${ }^{73}$.

No menos fiables considera Amador las noticias de ciertos vasos, lámparas, acetres y otros objetos de uso incierto, que las vagas descripciones de los informantes no supieron o quisieron despejar. Destaca aquel «cierta especie de cilindro de oro ornado de labores, que se dice tenía a uno de sus extremos un remate esférico de cristal de roca: los labriegos lo designaban con el nombre de «bastón de Recesvinto», $y$ algunos añadian que ostentaba también una cruz. ¿Seria tal vez un cetro, ofrecido por algún rey visigodo [...] como las coronas y bálteos?» ${ }^{74}$.

Sería incompleta la enumeración de joyas perdidas del Tesoro de Guarrazar sin la mención apuntada en el informe de D. Antonio Martín Gamero a la Real Academia de la Historia, de la que era correspondiente. Fué D.Antonio, como miembro de la Comisión Provincial de Monumentos, uno de los primeros en investigar los sucesos de Guarrazar, en la villa como en Toledo. Relatando el descubrimiento de las alhajas dice que encontraron unos vecinos de

\footnotetext{
$"$ Leclercq, H., ibidem. El texto es de la "vida de Saint Sauve».

72 Amador de los Ríos, J., op. cit., p. 124. Vid. tambièn Gómez-Moreno, M., op. cit., p. 337, donde se cita el mismo inventario de Celanova: "Cingulos aureos gematos II, alios argenteos exauratos ex quibus unum gematum "; el inventario de Compostela (911): "Balteum sacerdotale ex auro gemmis atque lapidibus constructum»; y el de Lugo (998): «Circulo cum baltheo argenteo et lapidibusn.

13 Amador de los Ríos, J., op. cit., p. 124.

14 Amador de los Rios, J., op. cit., p. 125, $n^{\circ} 2$. Meses antes de la publicación de Amador, en el doc. del M. de Fomento de 20-XII-1860, la comisión de compra se hacía eco del rumor de su existencia.
}

Guadamur, "según los mismos han referido, una especie de caldero, que, por creerle entonces de plomo, arrojaron y estuvo bastantes dias rodando por aquellas inmediaciones; y después un gran pedazo de oro compuesto de diferentes piezas aplastadas y del tamaño de una cabeza de toro [...] La figurada cabeza de toro fué entregada por los descubridores a D. Adolfo Herouart, con quien tenian relaciones intimas".

El informe de Gamero tiene fecha de 8-III-1859. Recoge varias de las versiones que sobre el hallazgo circulaban en Guadamur; la cita arriba transcrita está enmarcada en el relato que considera más verosímil. Parece sugerir que el caldero era en realidad de plata. Rada y Delgado lo afirma abiertamente ${ }^{75}$.

Una carta anónima, aparecida en la prensa toledana de la época, que atribuye el hallazgo del grueso del tesoro a Herouart, dice: «...logró el francés descubrir una caja, al parecer de plata, de figura de urna y de cerca de media vara de larga, la que oxidada enteramente, según él ha manifestado, se deshizo toda al ponerse en contacto con la atmósfera...." ${ }^{76}$.

IV. Hasta aqui las noticias sobre el hallazgo de piezas que se perdieron. La solvencia de algunas contrasta con la debilidad de otras. Pese a las diferentes apreciaciones de los testigos, las joyas vendidas por Manuela dejan suficiente constancia de su ser y forma; lo mismo puede afirmarse de los fragmentos descritos por Gamero. Las confidencias de Domingo de la Cruz a D. Antonio Flores, muy imprecisas, deben tenerse por sustancialmente verídicas y se ven corroboradas por testigos anónimos toledanos, que informaron a Amador,investigador meticuloso y ponderado. Paloma, cinturones y collares son objetos existentes en la cultura material de la época.

Diferente apreciación con reservas merece el informe de Martín Gamero. Cuando la Comisión Provincial de Monumentos, de la que era miembro, declara ante el Juez ${ }^{77}$, sobre el contenido de las actas de las sesiones relativas al tema de Guarrazar, dice que «los fundamentos en que estribaban sus acuerdos eran las noticias que corrían en la ciudad como ciertas o como probables, en rumor vulgar y que su celo no despreciaba por cuanto podian con-

\footnotetext{
${ }^{75}$ Rada y Delgado, J. de D., "Coronas de Guarrazar que se conservan en la Armeria Real de Madrid», en Museo Español de Antiguedades, 111, 1874, pp. 113-132: "[Una pobre mujer] halló piedras preciosas, trozos de oro y una especie de caldero que juzgó de hierro y luego resultó ser plata».

${ }_{76}$ Reproducida en Alonso Revenga, P. A., op. cit., pp. 26 y ss.

$"$ Decl. de 24-V1-1859.
} 
ducir a la averiguación de los sucesos...» La investigación judicial ignoró el hallazgo del supuesto caldero de plata, y lo mismo debe decirse de la caja/ urna que la carta anónima atribuye a los labios de Herouart. El comportamiento de éste en el asunto del tesoro dista mucho de ser honrado y sincero.

Más seguras son las deducciones extraidas de la observación de las alhajas fragmentadas y menudencias conservadas en los tres centros aludidos. Conviene advertir que los dos lotes primitivos del tesoro no se mantuvieron estancos, sino que, a través de los joyeros toledanos que compraron a ambos descubridores, se mezclaron piezas. Asi, objetos del conjunto de Domingo pudieron parar en manos de Navarro o Herouart, mediante las recuperaciones hechas a los plateros de la ciudad.

De lo arriba examinado se deducen como joyas perdidas, de las que hasta ahora no se tenia pública noticia, las siguientes:

- Un conjunto de fragmentos de lámina de pla$t a$, cuya conformación y peso sugieren con verosimilitud que habrían compuesto un cáliz $u$ otro recipiente sacro semejante.

- Un colgante de oro con piedras preciosas engastadas en forma de omega, que con el alfa del MAN. pendería de la gran cruz, dos de cuyas planchas de revestimiento se conservan en el mismo museo.

- «Una especie de cruz con engastes» (compra del platero Gamero).

Hemos intentado vislumbrar, ayudados por algunos documentos y por la comparación con la cruz de los Angeles, cómo estaría constituida la gran cruz de Guarrazar, joya excepcional en el conjunto, y su posible función de relicario. El mismo destino puede apuntarse (con mayor reserva) para el recipiente (cajita?) que decorarían como revestimiento las laminillas de plata con decoración repujada del MAN. La iconografía y estilo sugieren paralelos en relicarios paleocristianos y protobizantinos.

La macolla aislada que estuvo en el Palacio Real denuncia la existencia de otra corona muy semejante a la de Suintila, que se perdió en los crisoles toledanos. A ella pertenecerían una cruz colgante fragmentada, que fué sacrificada para completar la que adornaba a la corona de Suintila, y algunos eslabones de hoja de peral sueltos, conservados en Cluny y MAN.

De los conjuntos de piezas sueltas hay que separar primero las cadenas, de varios tipos:

a) las constituidas por eslabones de hoja de peral (tres vendidos a Gómez, dos en Cluny, y varios que compró Gamero), que suman al menos siete, pero debían ser más. Es probable que las cadenas de la corona de Suintila contaran con cinco eslabones (igual que la de Recesvinto), en vez de los cuatro que tenia cuando fué donada ${ }^{7 x}$; aún quedarian algunos destinados a suspender la corona perdida por Domingo de la Cruz.

b) Las cadenas con eslabones circulares alternando con otros en forma de 8 . Son de esta especie los dos fragmentos de N. Jean $\left(n^{\circ} 159\right)$ y otro $\left(n^{\circ} 158\right)$ de Herouart, en Cluny, y otros dos fragmentos en el MAN.

c) Cadenillas con eslabones revueltos en U. Pueden ser de este tipo los dos pedacitos de cadena de oro liso comprados por Gómez, pues apunta que el grueso del alambre era como de un alfiler común, y Mauricio Sánchez añade que los eslabones eran de dos clavos.

d) Finalmente, como indeterminados, aparecen los «tres trozos de cadena de eslaboncitos», comprados por Gamero.

Los eslabones del tipo $a$ ) que se conservan son sensiblemente iguales, mientras que los que componen las cadenas de los tipos $b$ ) y $c$ ) en las coronas y cruces de los museos varian en tamaño y grosor. Tampoco es constante la relación de un tipo de cadena con una determinada clase de joya; la tendencia es emplear las cadenas de eslabones revueltos en $U$ para unir la diadema de las coronas menores con el florón o anilla de suspensión, y las de elementos circulares alternados con otros en forma de 8 para colgar las cruces o las propias coronas a partir del florón o anilla. Pero no siempre se cumple. Queda la incógnita de la intervención restauradora de Navarro, condicionada por el material recuperado. Pero también es muy posible, como ya manifestó Amador $^{79}$, la coexistencia de talleres distintos en riqueza y medios; 'se fundaba en la muy baja ley del oro empleado en las coronas pequeñas y en la pobreza que reflejan algunos tipos en las inscripciones.

El florón aislado de Cluny, mencionado por Mérimée, pudo pertenecer a alguna de las coronas que no lo tienen; una de las de retícula del MAN recoge sus cadenas en una anilla, mientras que las otras dos cuelgan de sendas azucenas. Los pinjantes sueltos (dos en Cluny, tres en el MAN. y varios más en el Palacio Real) pueden llenar las pocas faltas que hoy tienen las preseas y clamar por alguna otra de la que fueron adorno.

\footnotetext{
78 Ambas coronas tienen idéntico diámetro $(22 \mathrm{~cm})$ Comparada con la de Recesvinto, más estética,la suspensión de la corona de Suintila resulta forzada y parece exigir cadenas algo más largas.

79 Amador de los Rios, J., op. cit., pp. 127 y ss. y notas.
} 
Paloma, háculo, cinturones y collares, sólo conocidos por testimonios orales anónimos, recogidos y calibrados por quienes anduvieron en las primicias de la investigación, completarian el tesoro perdido de Guarrazar, tesoro que, pese a las grandes amputaciones sufridas, continúa ostentando el primer lugar entre la orfebrería altomedieval. 